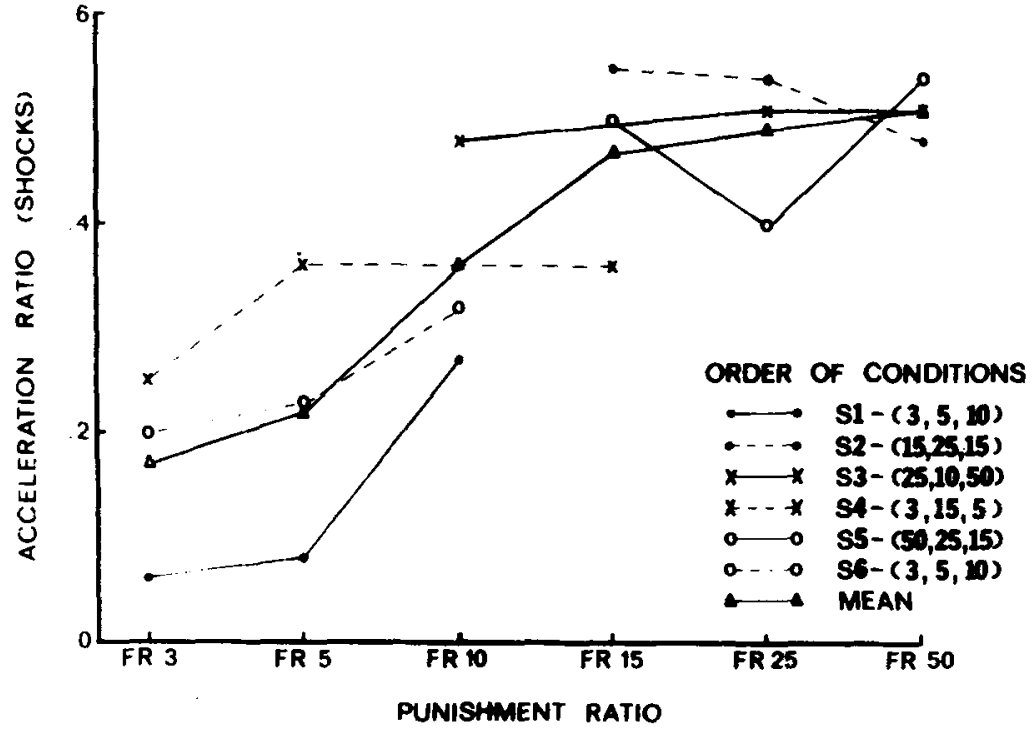

suppression. The data suggest that rats initially exposed to low ratios will show more suppression at higher ratios than will rats initially exposed to the higher ratios.

The effects on shock rate (Fig. 2) parallel those on response rate. FR values which produced response rate suppression also produced shock rate acceleration. This indicates that the effect of the punishment shocks was not to merely increase the efficiency of responding. Although there was a tendency for decreases in response rate to be greater than increases in shock rate, there are a few instances where substantial increases in shock rate are found without any noticeable decrease in response rate. This reflects a shift to a less efficient pattern of responding.

\section{DISCUSSION}

Punishment of avoidance results in an avoidance schedule in which the S.S parameter is kept constant while the R-S parameter at times becomes zero. Under such conditions, responding serves to increase the shock density of the situation. It is not surprising that responses subsequently become less probable or that the decrease in response probability is related to the degree to which responses increase shock density.

The responses which do not occur (i.e., are "suppressed" by the punishment contingency) are not randomly distributed. Both McIntire et al (1968) and Sandler et al (1966b) found that responses tended to occur in bursts following a shock. Such responses are commonly attributed to the escape training implicit or explicit in the early avoidance training and to a resultant eliciting property of the shock. Bursting, however, is inefficient, and in a ratio punishment situation, results in maximum increase in shock density. This suggests that if the change in shock density effected by the punishment contingency were the only controlling factor, bursting should be eliminated rather than maintained or enhanced. One factor which might account for the maintenance of bursting is the use of short S-S intervals and long R-S intervals. While bursting is inefficient relative to evenly spaced responding at the same overall rate, a response during the $S-S$ interval produces a greater and more immediate reduction in shock density than a response in the R-S interval.

This type of approach makes it clear that a meaningful statement of the effects of
CARL CHENEY and ROBERT CROW, Utah State University, Logan, Utah 84321

Light- and dark-reared rats received ablations of the superior colliculus, striate cortex, or both areas, and were later tested on a visual cliff. No significant difference in side preference was recorded between groups. Significantly more "no-descents" were recorded for the group undergoing the combined lesions, despite the use of a
Fig. 2. Shock-rate acceleration ratios for individual Ss and groups as a function of the punishment ratio.

punishment on avoidance responding requires parametric examination of avoidance schedule parámeters as well as punishment schedules parameters.

\section{REFERENCES}

AZRIN, N. H., HOLZ, W. C. \& HAKE, D. F Fixed-ratio punishment. Joumal of the Experimental Analysis of Behavior, 1963, 6, 141-148.

BOREN, J. J., SIDMAN, M., \& HERRNSTEIN, R. J. Avoidance, escape, and "extinction as functions of shock intensity. Journal of Comparative \& Physiological Psychology, 1959, $52,420-425$.

MCINTIRE, R. W., DAVIS, H., COHEN, S. I., \& FRANCH, E. O. Sidman avoidance performance under punishment and non-contingent shock conditions. Psychological Reports, 1968, 22, 897-903.

POWELL, R. W., \& MORRIS, G. Continuous punishment of free-operant avoidance in the rat. Journal of the Experimental Analysis of Behavior, 1969, 12, 149-157.

SANDLER, J., DAVIDSON, R, S., \& HOLZSCHUH, R. D. Effects of increasing punishment frequency on Sidman avoidance behavior. Psychonomic Science, 1966a, 5, 103-104.

SANDLER, J., DAVIDSON, R. S., GREENE, W. E., \& HOLZSCHUH, R. D. Effects of punishment intensity on instrumental avoidance behavior. Journal of Comparative \& Physiological Psychology, 1966b, 61, 212-216. SIDMAN, M. Avoidance conditioning with brief shock and no exteroceptive warning signal. Science, 1953, 118, 157-158.

\title{
Lesion effects on visual cliff performance in the rat $^{1}$
}

centerboard capable of inducing descents in the other Ss.

Depth discrimination, as indicated by visual-cliff performance, is present in many organisms at birth or within a short time the reafter (Walk \& Gibson, 1961). Behavioral studies have indicated both innate and learned components to visual discrimination (e.g., Gibson \& Walk, 1960), but little direct investigation has aimed at 
Table 1

Summary of Performance on the Visual Cliff for All Groups

\begin{tabular}{|c|c|c|c|c|c|}
\hline \multirow[b]{2}{*}{ Operation } & \multirow[b]{2}{*}{$\begin{array}{c}\text { Rearing Light } \\
\text { Conditions }\end{array}$} & \multirow[b]{2}{*}{$\mathbf{N}$} & \multicolumn{3}{|c|}{ Descent Preference } \\
\hline & & & Deep & Shallow & $\begin{array}{c}\text { No } \\
\text { Descent }\end{array}$ \\
\hline $\begin{array}{l}\text { Superior } \\
\text { Colliculus }\end{array}$ & $\begin{array}{l}\text { DR } \\
\text { LR }\end{array}$ & $\begin{array}{r}10 \\
5\end{array}$ & $\begin{array}{l}1 \\
0\end{array}$ & $\begin{array}{l}9 \\
5\end{array}$ & $\begin{array}{l}0 \\
0\end{array}$ \\
\hline Striate & DR & 10 & 0 & 10 & 0 \\
\hline Cortex & $\mathbf{L R}$ & 5 & 0 & 5 & 0 \\
\hline $\begin{array}{l}\text { Superior Colliculus } \\
\text { and Striate Cortex }\end{array}$ & $\begin{array}{l}\mathrm{DR} \\
\mathbf{L R}\end{array}$ & $\begin{array}{l}20 \\
10\end{array}$ & $\begin{array}{l}1 \\
1\end{array}$ & $\begin{array}{l}4 \\
1\end{array}$ & $\begin{array}{r}15 \\
8\end{array}$ \\
\hline $\begin{array}{l}\text { Sham } \\
\text { Operated }\end{array}$ & $\begin{array}{l}\text { DR } \\
\text { LR }\end{array}$ & $\begin{array}{r}10 \\
5\end{array}$ & $\begin{array}{l}1 \\
0\end{array}$ & $\begin{array}{l}8 \\
5\end{array}$ & $\begin{array}{l}1 \\
0\end{array}$ \\
\hline $\begin{array}{l}\text { Non- } \\
\text { Operated }\end{array}$ & $\begin{array}{l}\text { DR } \\
\text { LR }\end{array}$ & $\begin{array}{r}10 \\
5\end{array}$ & $\begin{array}{l}0 \\
0\end{array}$ & $\begin{array}{l}9 \\
5\end{array}$ & $\begin{array}{l}1 \\
0\end{array}$ \\
\hline
\end{tabular}

identifying the neural mechanisms were lightly anesthetized with sodium underlying depth discrimination. Many pentobarbital in subdued red-light structures probably involved in this conditions and treated as determined by discrimination have been suggested.

The present study was designed to bilateral and by way of visually guided investigate the role of superior-colliculus subpial aspiration. Individual operations and/or striate-cortex lesions in the required less than 20 min each. visual-cliff performance of the rat.

\section{SUBJECTS}

A total of 90 naive Long-Evans hooded rats of both sexes were included in this study. There were 40 experimental and 20 control S: all of which had been dark-reared, in addition to 30 light-reared Ss. The light-reared animals were raised under normal laboratory lighting conditions.

\section{APPARATUS}

The visual cliff was constructed with a 3-in.-wide centerboard of eight parallel copper rods, suspended 3 in. above a $3 \times 5 \mathrm{ft}$ sheet of heavy glass. The glass was bordered by 8 -in.-high boards painted flat gray. Under the glass were patterns of red and white $1 / 2$-in.-sq checks. The pattern on the shallow side was flush with the underside of the glass, while the deep-side pattern was suspended at a point $18 \mathrm{in}$. beneath the glass. Diffisse overhead lighting illuminated the centerboard and the patterns. The $O s$ viewed the cliff from behind screens located $8 \mathrm{ft}$ from the cliff centerboard. The copper-red centerboard was connected to a scrambled electric shock source. Shock intensity could be continuously varied from 0 to $5.0 \mathrm{~mA}$.

\section{PROCEDURE}

Experimental animals were raised in total darkness from within $4 \mathrm{~h}$ of birth until they were 30 days old. At that time, each $S$ was randomly assigned to one of the following groups: (1) superior-colliculus ablated, (2) striate-cortex ablated, (3) superior-colliculus and striate-cortex ablated, (4) sham operated, or (5) nonoperated. Thirty-day-old light-reared animals were also randomly assigned to the same treatment groups. All Ss, except for the nonoperated groups,

Performance differences of ablated animals as compared to control $S s$ are not significant $(p>.05)$, with the exception of the lightand dark-reared $S s$ with both superior-colliculus and striate-cortex ablations. The $S$ s receiving the combined operation showed a significant $(\mathrm{p}<.001)$ tendency not to descend, i.e., most of the Ss with combined ablations, regardless of rearing condition, remained on the centerboard throughout the test session. Operated animals included in these results were those in which the ablation was restricted to the prescribed area and $90 \%$ complete, or greater, as determined by histological analysis.

\section{DISCUSSION}

Statements concerning the individual importance of the superior colliculus or the striate cortex in basic visual tasks are not supported by the results of this study. To affirm that the critical innate mechanism of depth perception is functionally located in either the cortex or the superior colliculus is not allowed by the results. Rather, a statement of the importance of the integrity of either one or the other of these areas for normal visual-cliff performance is required. The apparent behavioral normality of all groups (except for the combined-lesion group) indicates that visual-cliff performance is not noticeably impaired by rearing conditions and/or ablation of either the striate cortex or the superior colliculus of the rat; however, abnormal cliff behavior results from the simultaneous ablation of both these neural structures, regardless of rearing condition.

of procedural significance are the relatively few no-descents recorded for all but the combined-operations groups. Earlier studies (e.g., Walk \& Gibson, 1961) have reported difficulties in obtaining results without the processing of large numbers of Ss due to an inability to induce choice behavior in immature Ss. Although several methods of forcing choice behavior have reportedly had some success (e.g., icetrays), the procedure used in this study seems maximally effective.

From the results, it can be concluded that dark-reared rats, at $\mathbf{4 0}$ days of age, discriminate depth on a visual cliff at the first opportunity. Further, visual-cortex or superior-colliculus lesions do not, by themselves, interfere with depth discrimination in either light- or dark-reared rats. Concurrent and simultaneous lesions of both these neural areas resulted in a functional "blindness" on the visual cliff in that Ss refrained from emitting choice behavior, i.e., they did not descend from the centerboard, even under conditions that induced descents from normal and other operated rats.

\section{REFERENCES}

GIBSON, E. J., \& WALK, R. D. The "visual cliff." Scientific American, 1960, 37, 2-9.

WALK, R. D., \& GIBSON, E. J. A comparative and analytical study of visual depth perception. Psychological Monographs, 1961, 75, (Whole No. 519).

\section{NOTE}

1. Supported by NSF Grant No. GB5977. 